\title{
Optimal design of an aeroelastic wing structure with seamless control surfaces
}

\author{
M Perera and S Guo* \\ Department of Aerospace Engineering School of Engineering, Cranfield University, Cranfield, Bedfordshire, UK
}

The manuscript was received on 16 December 2008 and was accepted after revision for publication on 9 July 2009.

DOI: 10.1243/09544100JAERO493

\begin{abstract}
This article presents an investigation into the concept and optimal design of a lightweight seamless aeroelastic wing (SAW) structure for small air vehicles. Attention has been first focused on the design of a hingeless flexible trailing edge (TE) control surface. Two innovative design features have been created in the SAW TE section: an open sliding TE and a curved beam and disc actuation mechanism. This type of actuated TE section allows for the SAW having a camber change in a desirable shape and minimum control power demand. This design concept has been simulated numerically and demonstrated by a test model. For a small air vehicle of large sweep back wing, it is noted that significant structural weight saving can be achieved. However, further weight saving is mainly restricted by the aeroelastic stability and minimum number of carbon/epoxy plies in a symmetric layup rather than the structural strength. Therefore, subsequent effort was made to optimize the primary wing box structure. The results show that an initial structural weight can be reduced significantly under the strength criterion. The resulting reduction of the wing box stiffness and aeroelastic stability and control effectiveness can be improved by applying the aeroelastic tailoring. Because of the large swept angle and resulting lightweight and highly flexible SAW, geometrical non-linearity and large bending-torsion aeroelastic coupling have been considered in the analysis.
\end{abstract}

Keywords: seamless aeroelastic wing, flexible trailing edge section, control effectiveness, aeroelastic tailoring

\section{INTRODUCTION}

The feasibility of active aeroelastic wing technology (AAWT) has been demonstrated and studied by many research programmes $[\mathbf{1}, \mathbf{2}]$. An alternative technology for achieving flapless flight of an unmanned air vehicle (UAV) is currently under development in the Flapless Air Vehicle Integrated Industry Research (FLAVIIR) programme [3]. The primary aim of the project reported in this paper is to design a seamless aeroelastic wing (SAW) structure applicable to a lightweight UAV. This article is focused on an optimal design of a SAW structure. Although similar to the AAWT and relevant to the FLAVIIR, one distinct difference from them is that a SAW will function as an integrated lifting surface with hingeless control

\footnotetext{
*Corresponding author: Department of Aerospace Engineering, Cranfield University, Cranfield, Bedfordshire MK43 OAL, UK. email:s.guo@cranfield.ac.uk
}

surface. Unlike the conventional hinged flap or unconventional coanda jet flow [3], SAW is designed to form a desirable wing camber for control by deflecting a hingeless flexible trailing edge (TE) section. The SAW concept has main advantages of improved aerodynamic efficiency (high lift/drag ratio, etc.), increased operational flexibility, less concentrated hinge load, and potential structure weight saving. The main challenge of this project is to design a feasible, simple, reliable, and lightweight SAW structure and its actuation mechanism.

In this current investigation, attention has been first paid to the design of a SAW with a flexible TE section as a hingeless control surface. Within the TE section, a curved beam and disc design based on a design concept [4] has been used. At the TE, an innovative open sliding TE has been designed for large TE deflection in desirable shape and minimum demand for control power. A physical model has been built to demonstrate and prove this design concept. For a lightweight and low-speed UAV, wing load is usually relatively small 
even with a large limit-load factor. For this kind of UAV having a large sweep back wing, significant structural weight saving is mainly constrained by aeroelastic stability and manufacture of carbon/epoxy composite rather than the usual strength criterion. Therefore further effort was made to optimize the SAW structure for a minimum weight and maximum aeroelastic stability.

Composite materials are employed for the wing structure mainly due to their favourable high specific strength and stiffness. In addition, fibre reinforced composites offer great potential for optimizing the fibre orientations and achieving desirable directional stiffness and aeroelastic behaviour with less weight penalty. Some previous work in aeroelastic tailoring has demonstrated that the divergent speed of a forward swept wing can be increased by optimizing the laminate layup [5-7]. The elastic or stiffness coupling due to an unsymmetrical laminate layup could also have significant effect on the aeroelastic behaviour of a composite wing $[\mathbf{8}, \mathbf{9}]$. Therefore investigations have been carried out in order to optimize the laminate layup of a composite wing structure for desirable aeroelastic behaviours [10-13]. Because of the flexibility and large sweep angle of the current SAW, flutter and control effectiveness are the main design constraints and bending-torsion stiffness coupling is a key design factor in aeroelastic tailoring.

Previous research has shown that a gradient-based deterministic method (GBDM) based on a continuous and finite gradient of objective function at each step of the process is suitable for aeroelastic tailoring $[14, \mathbf{1 5}]$. This method is computationally more efficient than a genetic algorithm (GA) method based on a stochastic procedure $[\mathbf{1 6}, \mathbf{1 7}]$. In this article, therefore, the GBDM is employed for the SAW structure optimization to achieve a lightweight, adequate strength, and aeroelastic stability design. The optimal design was conducted in two stages. First, effort was made to design and model a composite wing for a minimum weight structure option. An analytical method was used for structural stress, vibration, and aeroelastic analyses. The NASTRAN package based on the finite-element method (FEM) was also used for structural analysis and comparison. Second, attention was focused on aeroelastic tailoring of the basic composite wing model to achieve the maximum flutter speed under the strength criterion.

\section{SAW DESIGN}

Curved beam within a flexible TE section: an eccentric beam design concept for deflecting a flexible wing control surface was initiated by the DARPA Smart Wing project [18]. Eccentuation was a concept developed in the 1970s for variable camber control surfaces. This concept proposes a curved beam called an eccentuator to convert a rotational input motion into a vertical and lateral displacement at the output end (Fig. 1) [4, 17]. The output end of the curved beam is connected to a bearing surface moving up or down depending on the direction of the beam rotation. At $90^{\circ}$ rotation, the control surface is fully deployed, and zero actuation force is required because the entire external load is transferred into the substructure. One of the disadvantages in this design was the accompanying spanwise and chordwise lateral motion of the beam, which results in a sliding motion within a carrier cylinder [4]. Since this concept leads to a simple mechanism, it is adapted and improved in the current SAW actuation mechanism design. Figure 2(a) illustrates the current curved beam and disc configuration used to replace the above original design concept. Design improvement has been made in dealing with the beam lateral motion and connection to the skins. In this SAW design, discs are mounted on the beam and their edges are kept contact with the upper and lower skin stiffeners as illustrated in Fig. 2(a). The discs of different sizes along the beam are used to maintain the TE section shape as the beam rotates. The discs are mounted at different angles to the beam axis to keep the disc edges move in a straight track on the spanwise stiffeners for minimum chordwise sliding and friction. The actuator torque is distributed to the discs through the beam and converted to compressive forces acting on the skin stiffeners to bend the skin and deflect the TE section. The bending moment produced by the skin elastic force and aerodynamic pressure can be calculated in order to work out the required actuation torque and power.

To produce the required SAW TE deflection with minimum actuation power, an open TE has been designed to allow for a certain warping. As illustrated in Fig. 2(b), two metallic sheets are bonded to the TE upper and lower skin and one of the edges is folded to cover another. This open-edge design allows the

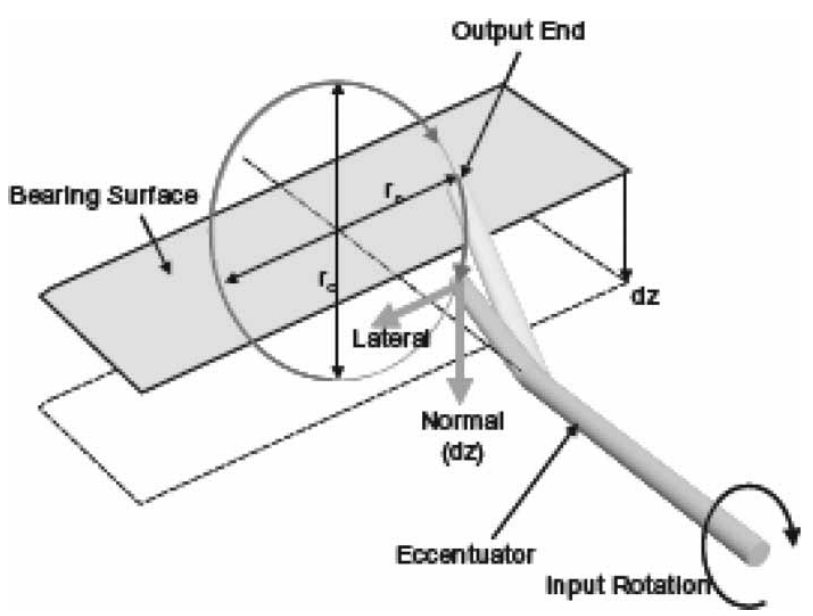

Fig. 1 The eccentuator mechanism [17] 


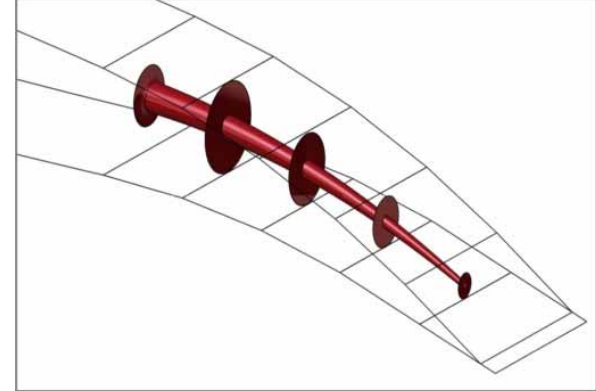

(a)

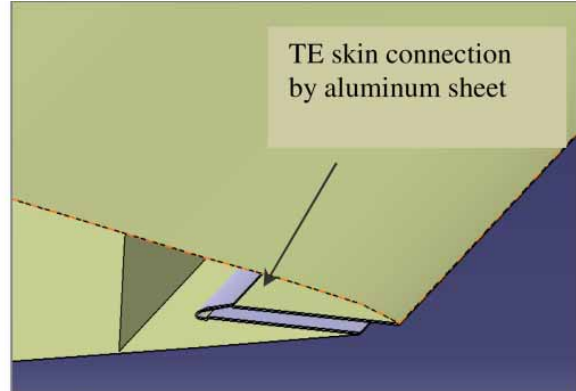

(b)

Fig. 2 (a) Schematic of curved beam disc actuation mechanism and (b) the SAW open TE design

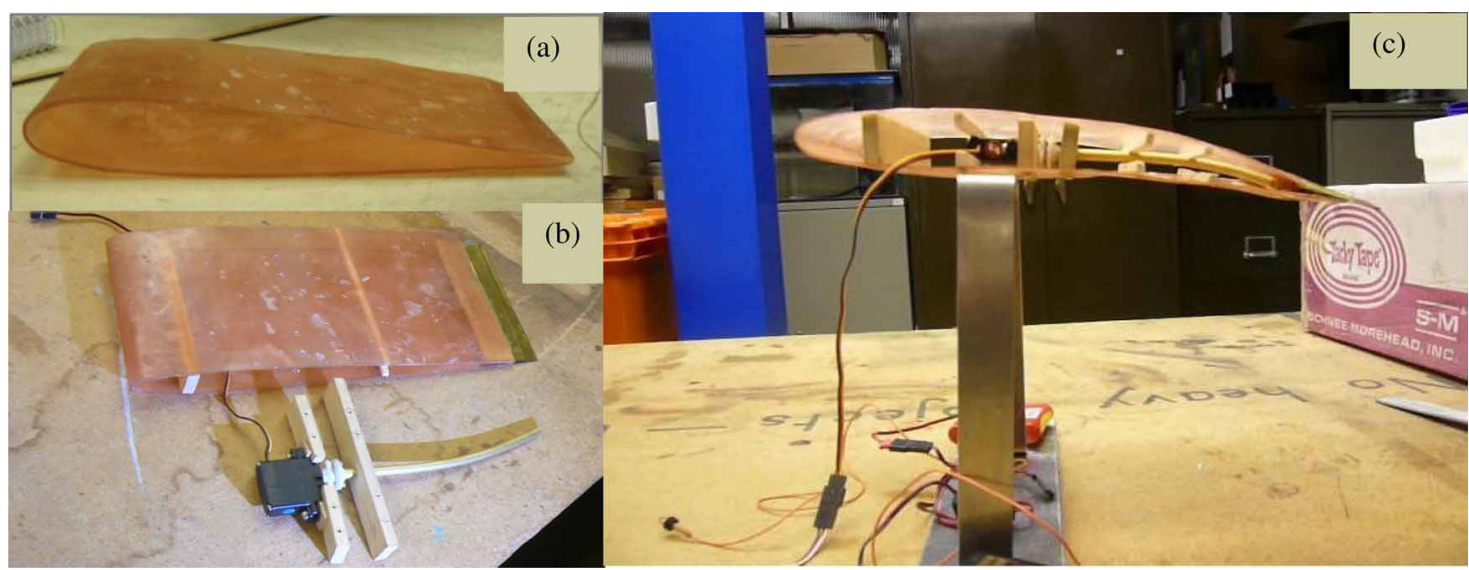

Fig. 3 (a) SAW skin model, (b) spars, motor, and curved beam, and (c) deflected SAW model

skins sliding relative to each other when the TE is being deflected.

To validate and demonstrate the design concept of the flexible TE section with curved beam actuation mechanism and open TE, a scaled SAW model made of glass/polyester composite was built as shown in Fig. 3. It is a NACA0015 airfoil section of $200 \mathrm{~mm}$ chordwise and $100 \mathrm{~mm}$ spanwise. The skin is made of four layers of glass fibre polyester prepreg in 0/90 layup. The spars and stiffeners are made of wood. The front spar is positioned at 20 per cent chord and rear spar at 50 per cent chord together with a mid spar at 40 per cent. A servomotor mounted to the mid spar produces a torque of $37.3 \mathrm{Nm}$ at $4.8 \mathrm{~V}$. A curved beam is connected to the motor and is supported by the rear spar through a bearing and connected to a skinstiffeners cover in the flexible TE section. These four stiffeners are in touch with the rotating beam, and thus transfer the actuating force to the skin bending action and TE deflection up or down in the required shape. Two more stiffeners are bonded to the skin above and below the motor to reinforce the skin and motor mounting against the reaction torque in operation. The deflected shape of the test model is shown in Fig. 3(c).

\section{ANALYTICAL METHODS}

\subsection{Structural model and analysis}

In this investigation, a full-scale sweep back rectangular wing model is created for a small UAV. The wing structure is made of the front and rear spars, ribs, and stringer reinforced skins. Based on the SAW design concept, most of the load on the flexible TE section is transferred to the rear spar through the curved beam. Since the wing box enclosed by the spars is the main load carrier, the modelling and analysis are focused on the wing box structure. In the structural model, the wing box was divided into a number of spanwise segments and each of them was modelled as a uniform thin-walled single-cell box beam as illustrated in Fig. 4, and the whole wing structure was modelled as an assembly of those box beams.

Based on the analytical method by Armanios and Badir [19], a relationship between the bending moment $M_{x}$, torque $M_{y}$, and the transverse and twist deflections at the end of an anisotropic thinwalled closed-section beam, as shown in Fig. 4(b), are expressed below

$$
M_{y}=C_{22} \phi^{\prime}+C_{23} h^{\prime \prime} \quad \text { and } \quad M_{x}=C_{23} \phi^{\prime}+C_{33} h^{\prime \prime}
$$




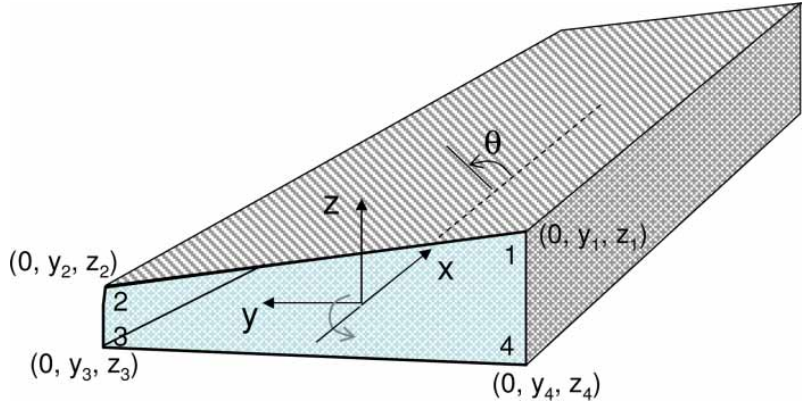

Fig. 4 Cross-section details of the wing box

The stiffness coefficients $C_{i j}$ of each segment can be calculated based on its geometry and material properties and integration along its cross-sectional circumference

$$
\begin{aligned}
C_{22} & =\frac{A_{\mathrm{e}}^{2}}{\oint[1 / C(s)] \mathrm{d} s} \\
C_{23} & =-A_{\mathrm{e}} \frac{\oint[B(s) / C(s)] z \mathrm{~d} s}{\oint[1 / C(s)] \mathrm{d} s} \\
C_{33} & =\oint\left[A(s)-\frac{B(s)^{2}}{C(s)}\right] z^{2} \mathrm{~d} s+\frac{\{\oint[B(s) / C(s)] z \mathrm{~d} s\}^{2}}{\oint[1 / C(s)] \mathrm{d} s}
\end{aligned}
$$

where $A_{\mathrm{e}}$ is the enclosed area of the cross-section; parameters $A(s), B(s)$, and $C(s)$ are given below

$$
\begin{aligned}
& A(s)=A_{11}-\frac{\left(A_{12}\right)^{2}}{A_{22}}, \quad B(s)=2\left(A_{16}-\frac{A_{12} A_{26}}{A_{22}}\right) \\
& C(s)=4\left[A_{66}-\frac{\left(A_{26}\right)^{2}}{A_{22}}\right]
\end{aligned}
$$

In the above equations, $A_{i j}$ are the coefficients of stiffness matrix (A) of the composite skin and spar webs of the closed-section beam. According to the force-deflection relationships in equation (1) and stiffness definition, the stiffness coefficients $C_{33}, C_{22}$, and $C_{23}$ actually represent the bending, torsion, and bending-torsion coupling rigidities of the wing box beam, which are usually expressed by symbols $E I, G J$, and $C K$, respectively. Contribution of the six stringers to the wing box bending stiffness is also included in the model.

The dynamic stiffness matrix method [20, 21] was subsequently used for the vibration analysis. In this method, the equations of motion for each of the thinwalled box beams were represented as follows, where the bending-torsion stiffness coupling was included but the transverse shear deformation and warping effect were neglected

$$
\begin{aligned}
& E I h^{\prime \prime \prime \prime}+C K \phi^{\prime \prime \prime}+m \ddot{h}-m X_{\alpha} \ddot{\phi}=0 \\
& G J \phi^{\prime \prime}+C K h^{\prime \prime \prime}+m X_{\alpha} \ddot{h}-I_{\mathrm{p}} \ddot{\phi}=0
\end{aligned}
$$

where $h^{\prime \prime \prime \prime}=\partial^{4} h / \partial y^{4}, \ddot{h}=\partial^{2} h / \partial t^{2}, \phi^{\prime \prime \prime}=\partial^{3} h / \partial y^{3}$, and $\ddot{\phi}=\partial^{2} h / \partial t^{2}$. By solving the differential equations, an exact solution for the transverse displacement $h(y)$ and twist $\phi(y)$ can be obtained. A dynamic stiffness matrix for a box beam can be subsequently created by relating the displacements to the bending moment and torque at both ends of the beam. A dynamic stiffness matrix for the whole wing box structure is obtained by assembling all the wing box beam stiffness matrices along the wing span direction.

The stress distribution at the wing root section was used to evaluate the local forces acting on the skin laminate at the critical region. Based on the force, stresses and failure index (FI) in each ply of the skin laminate were calculated based on the laminate theory [22].

\subsection{Aeroelastic analysis}

It is noted that the dynamic stiffness matrix is actually a combination of stiffness and mass matrices of the beam and is frequency dependant [14]. Since this particular type of matrix produces a non-standard eigenvalue problem, it is solved by using the WittrickWilliam algorithm [23]. By employing the normal mode method, the flutter equation for a wing can be written in generalized coordinates as

$$
\begin{gathered}
\left\{\left[\mathbf{K}_{\mathrm{D}}(\omega)\right]-\frac{1}{2} \rho V^{2}[\mathbf{Q A}]_{\mathrm{R}}+\mathrm{i} \omega[\mathbf{D}]\right. \\
\left.+\mathrm{i} \frac{1}{2} \rho V^{2}[\mathbf{Q A}]_{\mathrm{I}}\right\}\{\boldsymbol{q}\}=0
\end{gathered}
$$

The unsteady aerodynamic forces were calculated by using the classical Therdorsen theory $[\mathbf{2 4}, \mathbf{2 5}]$ and the strip method use in incompressible airflow. The above equation was solved for flutter speed by using the $V-g$ method in an iterative process. For static aeroelastic analysis, the aerodynamic coefficients for each of the wing sections with deflected TE are calculated by employing the panel method [24]. By the assembly of the spanwise beam models and twodimensional aerodynamic forces, the static aeroelastic equation of the wing can be established and written in matrix form as

$$
[\mathbf{K}]\{\boldsymbol{d}\}=\left[\boldsymbol{A F}\left(d, \delta_{\mathrm{TE}}, \delta_{\mathrm{LE}}\right)\right]
$$

where $[\mathbf{K}]$ is the stiffness matrix of the whole wing, vector $\{\boldsymbol{d}\}$ contains the wing box beam transverse displacement $h$ and twist $\phi ;\left\{\boldsymbol{A F}\left(d, \delta_{\mathrm{TE}}, \delta_{\mathrm{LE}}\right)\right\}$ is the vector of aerodynamic lifting force and pitching moment acting on the wing, which depends on $\{\boldsymbol{d}\}$ especially the twist angle, and the flexible TE and LE section deflections $\delta$. For the highly flexible and large sweep angle SAW, a geometrically non-linear and large bendingtorsion coupled deformation is expected. Equation (7) is expressed in the following form and solved in an 
iterative procedure

$$
[\mathbf{K}]\left\{\boldsymbol{d}_{j+1}\right\}=\left[\boldsymbol{A F}\left(d_{j}, \delta_{\mathrm{TE}}, \delta_{\mathrm{LE}}\right)\right]
$$

\subsection{Optimization method for aeroelastic tailoring}

In the optimization, the GBDM is employed for the SAW aeroelastic tailoring. Effort is primarily focused on achieving a maximum flutter speed by altering the fibre orientations of the skin and spar web laminates. Since the wing weight will not be altered, the analysis can be expressed as follows

$$
\begin{aligned}
& \text { Minimize } f_{\mathrm{v}}(x)=\left[1-\frac{V_{\mathrm{f}}(x)-V_{\mathrm{f}}\left(\theta_{0}\right)}{V_{\mathrm{f}}\left(\theta_{0}\right)}\right]^{2} \\
& x \in\left[A\left(\theta_{1}, \theta_{2}, \ldots, \theta_{n}\right)\right], \theta_{n} \in[-90,90]
\end{aligned}
$$

where $f_{\mathrm{v}}(x)$ is the objective function, $V_{\mathrm{f}}(x)$ is the wing flutter speed, $\boldsymbol{x}$ is a vector containing the fibre orientations $\left(\theta_{1}, \theta_{2}, \ldots, \theta_{n}\right)$ as design variables with lower and upper bounds of $\pm 90^{\circ}, \theta_{0}$ represents a set of specified fibre orientations in the initial layup of the skin and spar webs.

\subsection{Control effectiveness}

The flexibility of a wing adversely affects the effectiveness of the control surface. As expressed in equation (10) [26], a small increase in $\Delta L$ is produced by a positive aileron (TE downward) rotation angle $\delta_{\mathrm{TE}}$ and a positive (nose-up) wing twist angle $\phi$ due to elastic deformation of the wing

$$
\Delta L=\left(\frac{\partial C_{\mathrm{L}}}{\partial \alpha} \phi+\frac{\partial C_{\mathrm{L}}}{\partial \delta_{\mathrm{TE}}} \delta_{\mathrm{TE}}\right) \frac{1}{2} \rho V^{2} S
$$

For a 'rigid' wing with the elastic twist ignored, the increase of lift due to $\xi$ becomes

$$
\Delta L_{\mathrm{R}}=\frac{\partial C_{\mathrm{L}}}{\partial \delta_{\mathrm{TE}}} \delta_{\mathrm{TE}} \frac{1}{2} \rho V^{2} S
$$

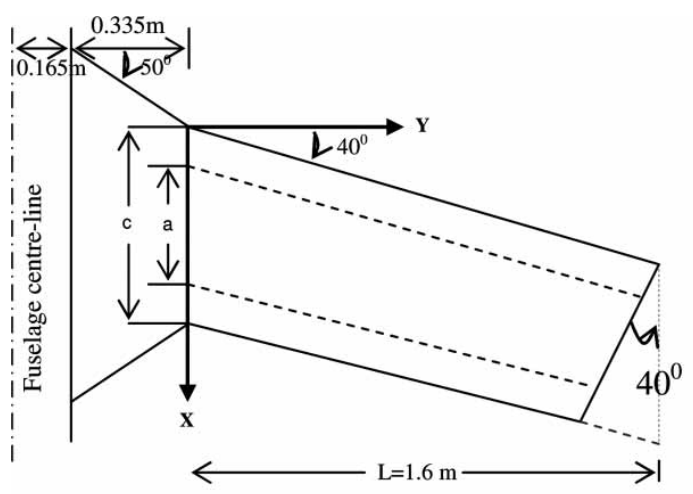

(a)
The ratio of $\Delta L$ to $\Delta L_{\mathrm{R}}$ is defined as the aileron effectiveness to assess the control effectiveness of a flexible wing

$$
\text { Aileron effectiveness }=\frac{\Delta L}{\Delta L_{\mathrm{R}}}
$$

Two types of forces cause the wing elastic twist. One is the aerodynamic torque induced by the lift and wing bending-torsion coupling deformation. For a sweep back wing, the induced twist angle is normally negative (nose-down). Another is the aerodynamic pitching moment $M_{0}$ about the wing elastic centre associated with the lift. It is normally positive for a general case that the aerodynamic centre is forward of the elastic centre. Both the aerodynamic torque and pitching moment vary with the flight speed. When flight speed increases, the wing elastic restoring moment may not be sufficient enough against the negative twist of the wing because of the TE rotation downward. Consequently, the effective aileron incidence [26] and aileron effectiveness and lift are reduced. When aileron reversal speed is reached, an aileron rotation produces zero rolling moment.

For the structural analysis and aeroelastic tailoring, a set of in-house developed computer programs based on the aforementioned analytical methods has been used. In addition, MSC PATRAN/NASTRAN code was also employed. Detail structural components such as stringers and ribs were also included in the SAW FE model. The FE stress and deflection results are used to compare with the analytical results.

\section{EXAMPLES AND RESULTS}

\subsection{Wing loading condition}

A SAW planform as shown in Fig. 5 designed for a small UAV of maximum take-off mass $70 \mathrm{~kg}$ is taken as an example. The cruise speed is $40 \mathrm{~m} / \mathrm{s}$ and dive speed $60 \mathrm{~m} / \mathrm{s}$. The design ultimate load factors are +4.2 and $-1.5 \mathrm{~g}$, respectively, which is mainly because of

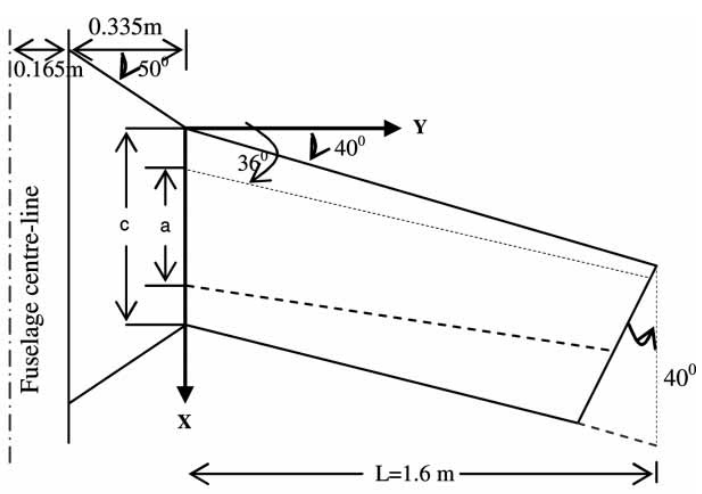

(b)

Fig. 5 (a) Initial wing box 1 configuration and (b) a reduced swept angle wing box 2 configuration 
Table 1 Geometric details of the wing model

\begin{tabular}{llllllll}
\hline Section & & $a(\mathrm{~m})$ & $b(\mathrm{~m})$ & $c(\mathrm{~m})$ & $h_{1}(\mathrm{~m})$ & $h_{2}(\mathrm{~m})$ & Aerofoil \\
\hline Wing box 1 & Root & 0.18 & 0.24 & 0.60 & 0.117 & 0.048 & NACA 0015 \\
& Tip & 0.18 & 0.24 & 0.60 & 0.036 & 0.027 & NACA 0006 \\
Wing box 2 & Root & 0.27 & 0.18 & 0.60 & 0.116 & 0.072 & NACA 0015 \\
& Tip & 0.27 & 0.30 & 0.60 & 0.021 & 0.032 & NACA 0006 \\
\hline
\end{tabular}

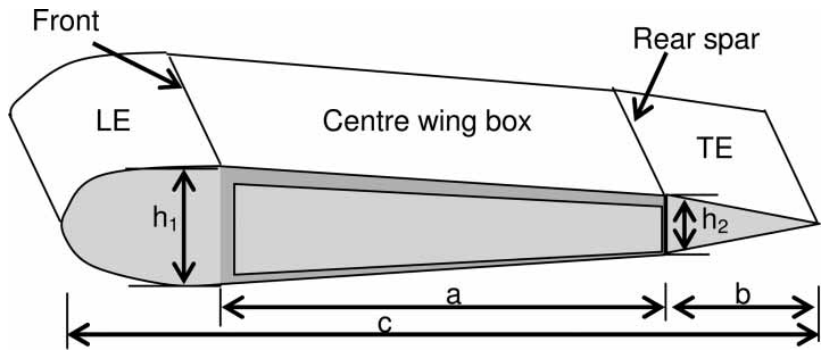

Fig. 6 Cross-sectional details of the wing box

the gust load. This makes the wing structure experience the total shear force of $1015.89 \mathrm{~N}$ and maximum bending moment of $874.59 \mathrm{Nm}$ at ultimate load $4.2 \mathrm{~g}$. This maximum load causes a concern in strength in the initial design. In addition, the large sweep back angle of $40^{\circ}$ causes another concern in aeroelastic stability.

\subsection{SAW structure design and analysis}

The SAW structure comprises a centre wing box and the LE and TE sections. The centre wing box is made of the front and rear spars and skins reinforced by six $T$-shape stringers, three on the upper and three on the lower skin. Two structural configurations are considered in the current design. Figure 5(a) shows an initial design with the usual spar arrangement. Figure 5(b) shows an alternative configuration with the spars and stringers relocated to reduce the sweep angle of the wing box elastic axis. It was found that this alternative design was better in terms of aeroelastic stability, especially the control effectiveness with details presented in section 4.5. This is because of the increased bending and torsion stiffness, but reduced coupling for the same wing planform. The results presented in the subsequent sections are for the improved wing box (wing box 2) configuration. Table 1 and Fig. 6 present the dimensions of the two types of wing box. In the structural model, the wing box was clamped at the root section and was divided into eight spanwise single-cell box beam segments.

\subsubsection{Initial design (Case 1)}

The initial design was taken as a baseline example, in which the wing skin and spars are made of 8-ply carbon/epoxy laminate of symmetric layup $[0 / 45 / 90 /-45]_{\mathrm{s}}$ with a skin thickness of $1 \mathrm{~mm}$. The stringers have the same material and thickness as the skin. The material properties are listed in Table 2. By applying the methods described in section 3, the calculated maximum stress of $22.1 \mathrm{MPa}$ indicates that initial design of the SAW structure is too conservative in terms of strength. The calculated flutter speed of $376 \mathrm{~m} / \mathrm{s}\left(>1.2 V_{\mathrm{D}}\right)$ and control reversal speed of $150 \mathrm{~m} / \mathrm{s}\left(>V_{\mathrm{D}}\right)$ also satisfy the JAR-VLA (629-aeroelastic requirement).

\subsubsection{Reduced weight design (Case 2.1, 2.2, and 2.3)}

To reduce the SAW structure weight, an alternative design was made. In this case, the material and layup of the spars remain the same, but the skin and stringers are reduced to two layers of unidirectional $E$-glass/epoxy. The change of material is mainly due to the constraint on the number of carbon/epoxy plies in a symmetric layup. Because the composite was cured at elevated temperature, unsymmetrical layup will cause thermal distortion. Since the $E$-glass/polyester can be cured at room temperature, unsymmetrical layup will not cause this problem. This gives flexibility in material thickness. Three different glass/polyester initial laminates were used, i.e. [0/90] for case 2.1, [ $+45 /-45]$ for case 2.2 , and $[+20 /-20]$ for case 2.3 were considered. Material properties of the $E$-glass/epoxy used in the analysis are listed in Table 2 . In both cases, the skin thickness was reduced to $0.5 \mathrm{~mm}$ and the wing box structural weight was reduced by approximately 30 per cent compared with the initial design.

To provide further details of the design, case 1 was also modelled by using the NASTRAN code. The FE models were created to represent the SAW box structure first as shown in Fig. 7(a), and followed by the whole SAW model including LE and TE section, as shown in Fig. 7(b). The TE section is integrated with

Table 2 Mechanical properties of carbon/epoxy and E-glass/epoxy

\begin{tabular}{lllllllllll}
\hline Material & $E_{1}(\mathrm{GPa})$ & $E_{2}(\mathrm{GPa})$ & $G_{12}(\mathrm{GPa})$ & $v_{12}$ & $X_{t}(\mathrm{MPa})$ & $X_{c}(\mathrm{MPa})$ & $Y_{t}(\mathrm{MPa})$ & $Y_{c}(\mathrm{MPa})$ & $S(\mathrm{MPa})$ & $\rho\left(\mathrm{Kg} / \mathrm{m}^{3}\right)$ \\
\hline Carbon/epoxy & 135 & 9.5 & 4.9 & 0.3 & 1680 & 1100 & 61 & 244 & 90 & 1600 \\
E-glass/epoxy & 40 & 8.0 & 4.0 & 0.25 & 1000 & 600 & 30 & 110 & 40 & 1900 \\
\hline
\end{tabular}




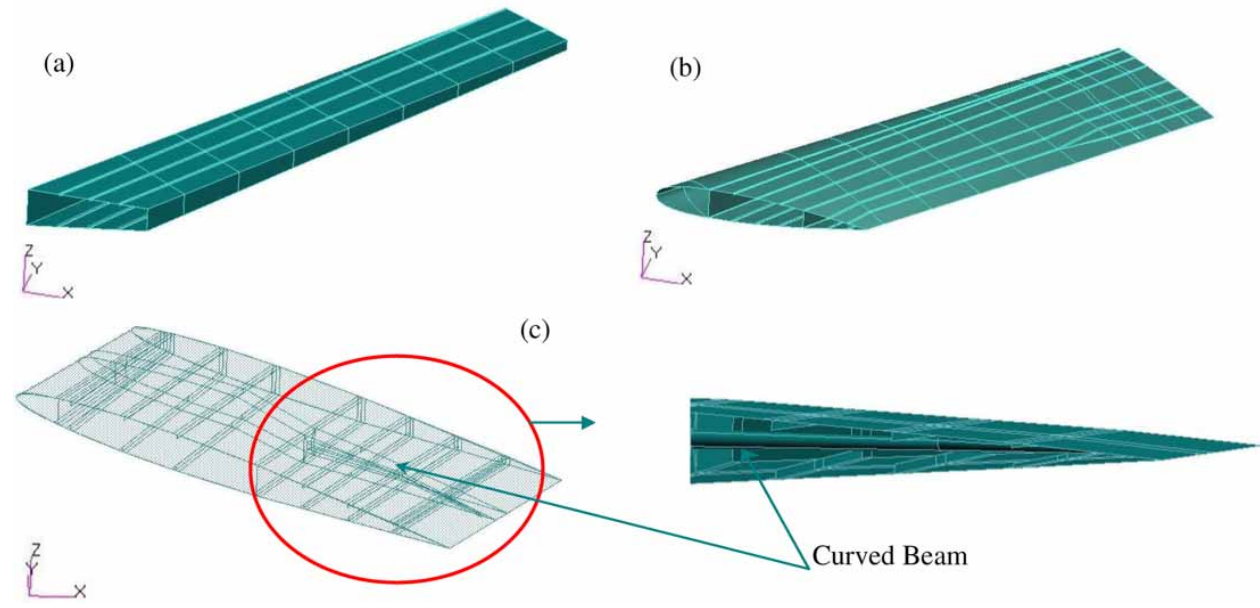

Fig. 7 (a) The wing box, (b) the whole wing of the SAW, and (c) the TE section with proposed actuation mechanism for the SAW

Table 3 Maximum displacement for case 1 - FE models

\begin{tabular}{ll}
\hline Case 1-FE models & $Z$-displacement (mm) \\
\hline SAW box model (case 1.1) & 15.3 \\
SAW with actuation mechanism and & 9.4 \\
$\quad$ closed TE (case 1.2) & \\
SAW with actuation mechanism and & 10.6 \\
$\quad$ open TE (case 1.3) & \\
\hline
\end{tabular}

the actuation mechanism adapting the same design concept as shown in the scaled demonstrator (see Fig. 3). The connection of the discs to the skin stiffeners were modelled using RBE2 elements in the FE models. The whole wing model was further analysed with a closed and open TE where the proposed actuation mechanism is integrated. Table 3 summarizes the maximum transverse deflections at the wing tip under the maximum load factor of $4.2 \mathrm{~g}$ for these cases.

\subsection{Laminate stress analysis}

First the thin-walled box method and laminate theory were used to calculate the average stress through the laminate thickness and then the stress and FI of each ply. In the approximate method, the maximum normal stress is expected to occur on the skins close to the front spar and shear stress in the spar web, respectively. The ultimate load factor of $4.2 \mathrm{~g}$ was applied.

For the initial design case 1 (carbon/epoxy material), the maximum average normal stress $22.1 \mathrm{MPa}$ of the lower skin and shear stress $3.72 \mathrm{MPa}$ in the web was converted to a local force intensity of $22.1 \mathrm{kN} / \mathrm{m}$ and shear force intensity $3.72 \mathrm{kN} / \mathrm{m}$. Those forces were used for further detailed stress calculation in each laminate ply and the FI based on the classic laminate theory. The resulting maximum Hoffman FI of 0.06 in the $90^{\circ}$ ply indicates that the initial design case 1 is too conservative and obviously over designed in terms of strength.

For the design cases 2.1, 2.2, and 2.3 (glass/epoxy skins), the maximum normal and shear stresses located in the same region of the skin laminate at the root section as case 1 are 35.26 and $7.58 \mathrm{MPa}$, respectively. The resulting maximum Hoffman FI of 0.02 in the skin laminate indicates that the wing box design still has plenty of strength reserves and shows the potential for design optimization and further structural weight reduction.

FE analysis using NASTRAN was carried out for more accurate and detailed stress analysis of the SAW. These results are listed in Table 4 together with the results obtained from the analytical method presented in section 3. The comparison indicates that the FE and analytical stress results in the specified region agree very well. However, two major differences are noted in the comparison. First, although the FE stress is distributed and more detailed, the comparison with analytical result can only be made in the same region and ply rather than point to point. Second, the FE model also considered the structural coupling effect (sweep angle) and the stress concentration effect. Therefore the stress on the skin near the rear spar

Table 4 Maximum direct and shear stresses for study cases 1-2

\begin{tabular}{llllrr}
\hline Design case & $\begin{array}{l}\text { Case 1 } \\
\text { (analytical) }\end{array}$ & $\begin{array}{l}\text { Case 2.1-2.3 } \\
\text { (analytical) }\end{array}$ & $\begin{array}{l}\text { Case 1.1 } \\
\text { (FEM) }\end{array}$ & $\begin{array}{l}\text { Case 1.2 } \\
\text { (FEM) }\end{array}$ & $\begin{array}{l}\text { Case 1.3 } \\
\text { (FEM) }\end{array}$ \\
\hline Direct stress (MPa) & \pm 22.1 & 35.3 & $19.4 /-20.1$ & 25 & 24 \\
Shear stress (MPa) & 3.73 & 7.60 & 1.72 & 2.31 & 1.88 \\
Hoffman failure index & 0.06 & 0.02 & 0.04 & 0.07 & 0.02 \\
\hline
\end{tabular}


and at the sharp corner of the FE model cannot be predicted by the analytical method.

FE analysis was also conducted for detailed stress calculation of the curved beam in the actuation mechanism under the maximum actuation force required to deflect the TE equivalent to $10^{\circ}$ of conventional flap deflection. The results indicate that a maximum stress of 5.8 MPa occurs around the connection of the curved beam to the rear spar.

Since the SAW design case 2 is still very conservative in terms of strength, attention was subsequently paid to the stiffness and aeroelastic stability.

\subsection{Aeroelastic tailoring}

Aeroelastic tailoring has been carried out by optimizing the SAW skin laminate layup to find an optimal combined bending and torsion stiffness for aeroelastic stability without increasing the weight and violating the strength criterion. Only the lightweight design case 2.1 ([0/90] skin), 2.2 ([ \pm 45$]$ skin), and $2.3([ \pm 20]$ skin) were considered. In the model, each section of the eight spanwise segments of the wing model was divided into four laminate panels representing the upper and lower skins, and front and rear spar webs along the thin-walled box cross-section circumference. It results in 32 pieces of laminate panels and 160 plies in the model. If the ply fibre orientations were taken as an independent design variable, then there would be 160 design variables in the optimization process. However, the design variables can be reduced under specified conditions. These analyses are reported below.

\subsubsection{Case $2.1[0 / 90]$}

Eight ply orientations were taken as design variables including two in the upper skin, two in lower skin, and two in each of the spar web panels at the root section. The laminates in the rest of the seven spanwise sections were kept the same as the optimized root section during the optimization. This condition keeps the laminate layup uniform along the spanwise wing box for easy manufacture. When the laminates were optimized, the flutter speed $V_{\mathrm{f}}$ was increased from its original $123 \mathrm{~m} / \mathrm{s}$ up to $169.7 \mathrm{~m} / \mathrm{s}$ (Table 5). Summary of the optimized laminate layups at root section and the flutter results are given in Table 5. A comparison between the initial and optimized rigidities of the section along the SAW span is shown in Fig. 8. The tip section is marked as point 1 and the root section is marked as point 8 .

\subsubsection{Case $2.2[ \pm 45]$}

Similar to the previous case, the eight plies (two for each of the four laminate panels) at the root section were taken as design variables. The layups of the eight spanwise sections were kept uniform in the optimization. The flutter speed of the initial skin layup $[+45 /-45]$ is $318 \mathrm{~m} / \mathrm{s}$. Following the optimization, a slightly higher value of $321 \mathrm{~m} / \mathrm{s}$ was achieved. Details of the initial and optimized design results are shown in Table 5. A comparison of the initial and optimized rigidities of the wing box along the span is shown in Fig. 8.

\subsubsection{Case $2.3[ \pm 20]$}

Started from this particular initial layup, the optimization was carried out with the same design variables similar to the previous cases. The laminates in the rest of the seven spanwise sections were kept uniform as the optimized root section during the optimization. The flutter speed for the optimized layup was increased from 162 to $189 \mathrm{~m} / \mathrm{s}$. The optimized laminate layups at the root section together with the flutter

Table 5 Optimized laminate layups, rigidity, and flutter speed in cases 2.1, 2.2, and 2.3

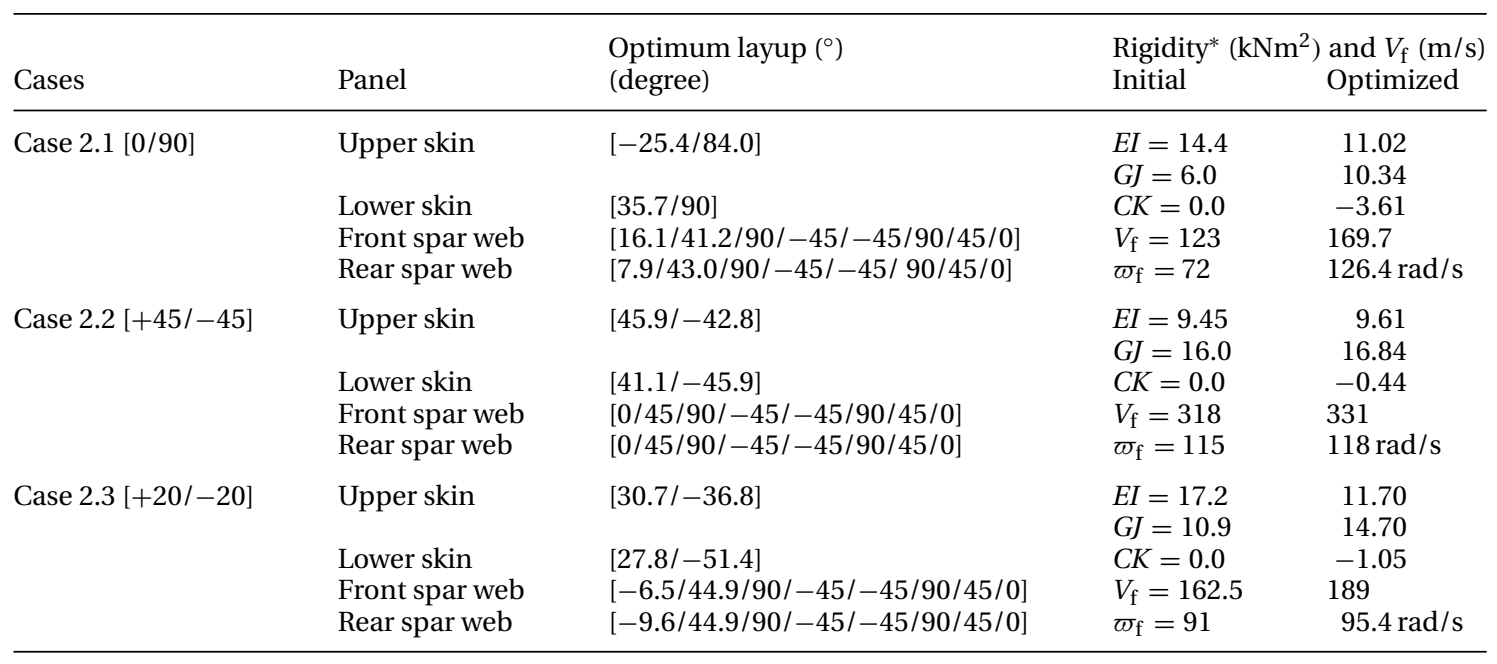

*Optimum layups and the optimum rigidities are for the root section. 

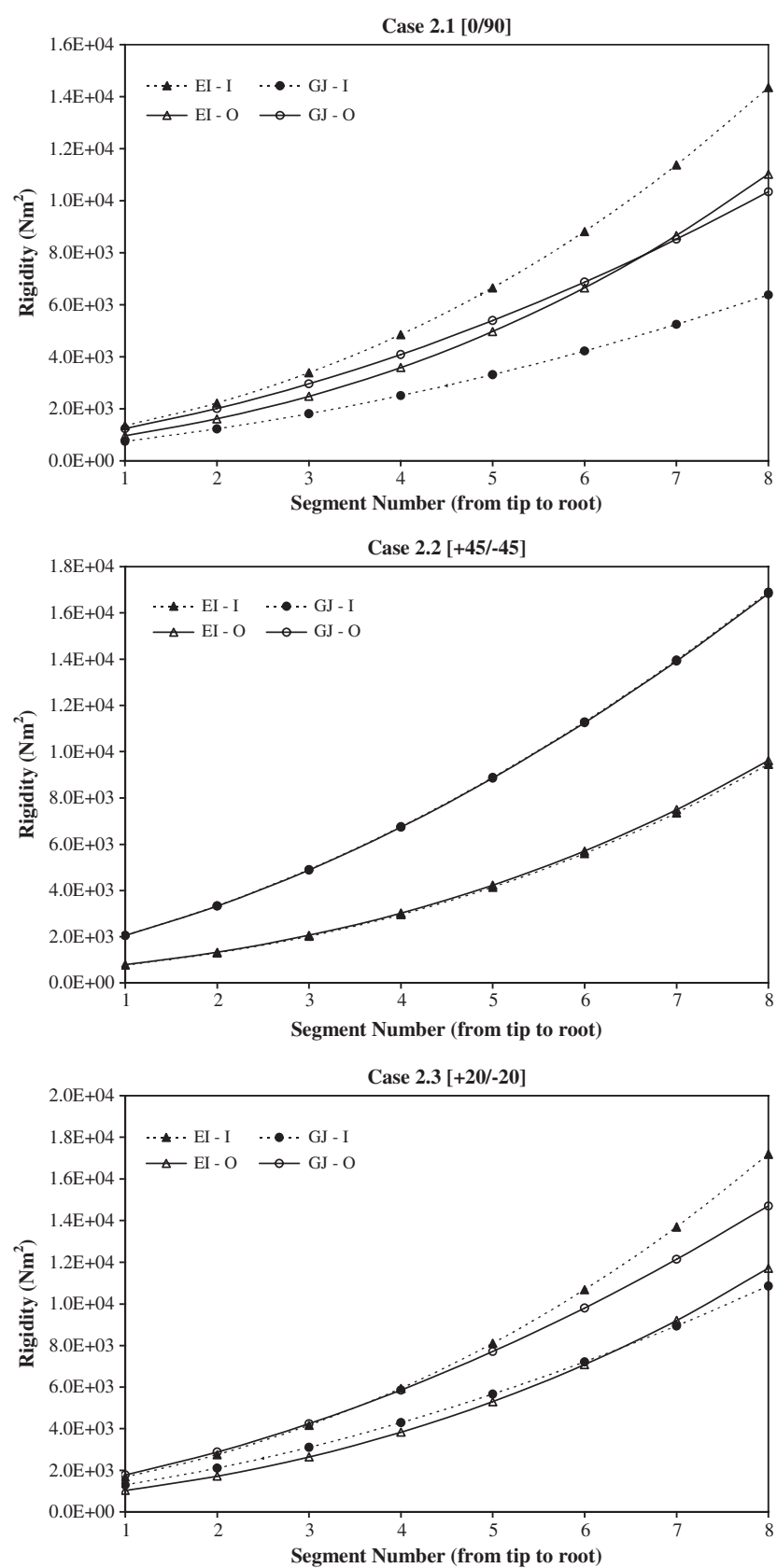

Fig. 8 Comparison of structural rigidities of the SAW box for the initial (I) and optimized (O) designs. Note: $\mathrm{EI}-\mathrm{I}=$ initial rigidity and $\mathrm{EI}-\mathrm{O}=$ optimized rigidity

results are summarized in Table 5 . Figure 8 summarizes the initial and optimized rigidities of the wing box along the span.

The box section rigidities shown in Fig. 8 indicate that the design case $2.3([+20 /-20]$ layup) has a greater EI than that of case 2.1 ([0/90] layup) and case 2.2 ([ \pm 45$]$ layup). Case 2.2 resulted in a higher $G J$ than that of case 2.1 and case 2.3. This was expected considering the layup difference. From the rigidity comparison presented in Fig. 8, the following observations are made. First the rigidities remain reduced along the

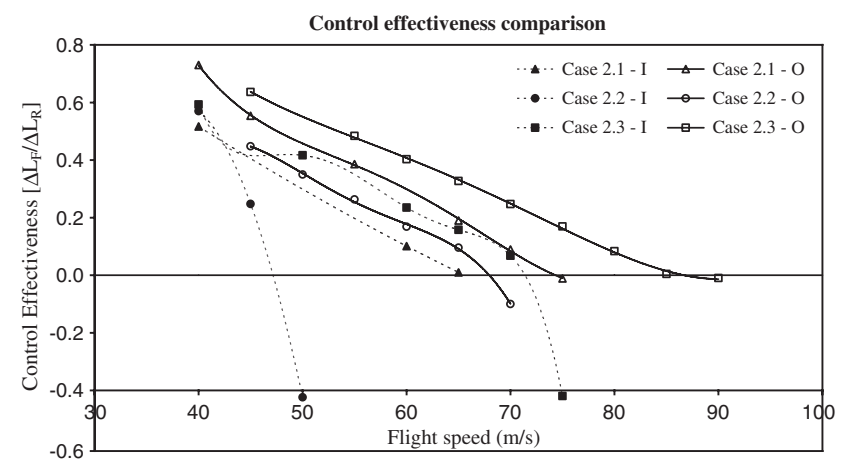

Fig. 9 Control effectiveness comparison of the initial (I) and optimized $(\mathrm{O})$ cases

wing span as the wing box is tapered down in all three cases; second the optimized $G J$ becomes greater and EI lower than those of the initial layup; finally the bending-torsion coupling rigidity $\mathrm{CK}$ produced from an optimized asymmetric layup plays a beneficial role in favour of the flutter speed. It is also noted that the aeroelastic tailoring is much more effective by optimizing the skin and web layups around the wing box section circumference rather than along the spanwise section.

\subsection{Control effectiveness}

The control effectiveness of the whole wing takes into account the swept angle and elastic twist effect. The control effectiveness results over a flight speed range for case 1 and optimized cases 2 are obtained by using equations (10) to (12). Control reversal speed $V_{\mathrm{R}}$ of design case 1 was $145 \mathrm{~m} / \mathrm{s}$. Figure 9 shows that the reversal speeds have been increased as a result of the aeroelastic tailoring. However, for the optimized design case $2.1[0 / 90] V_{\mathrm{R}}$ is significantly low at $75 \mathrm{~m} / \mathrm{s}$. For optimized case $2.2[+45 /-45], V_{\mathrm{R}}$ is further reduced to $70 \mathrm{~m} / \mathrm{s}$. The reversal speed for optimized case $2.3[+20 /-20]$ remains higher compared to cases 2.1 and 2.2 at $85 \mathrm{~m} / \mathrm{s}$.

For all three cases $2.1,2.2$, and 2.3 , the lower $V_{\mathrm{R}}$ is mainly due to the lower $G J$ compared to case 1 . Although case 2.2 has a greater $G J$ compared to case 2.1 , the $V_{\mathrm{R}}$ is even lower. This is mainly due to lower $E I$ in case 2.2 and the strong bending-torsion coupling of the flexible wing box. The reduced EI induced a nose down twist and resulted in a lower $V_{\mathrm{R}}$. Therefore an optimal layup with both greater EI and GJ should be a better solution. Since the optimized case 2.3 met this requirement, the resulting $V_{\mathrm{R}}=85 \mathrm{~m} / \mathrm{s}$ was indeed higher than the other two cases. Despite the $V_{\mathrm{f}}=189 \mathrm{~m} / \mathrm{s}$ of this solution being lower than case 2.2 , it is higher compared to the first option of case 2.1 and gives adequate safety margin for aeroelastic stability. 


\section{CONCLUSIONS}

In this article, a new design concept of SAW structure and actuation mechanism has been presented and analysed. Mechanically the design provides a simple and feasible actuation solution. Structurally it offers a lightweight solution. Because of the relatively low stress level at the $4.2 \mathrm{~g}$ ultimate load factor, the structural strength has enough safety margin for even two layers of glass/epoxy skin laminate. However, the reduced wing box stiffness leads to a significant reduction of aeroelastic stability in terms of flutter speed and control reversal speed. This is solved by performing an aeroelastic tailoring with optimum solutions. It is found that both the flutter and control reversal speeds are dominated by the torsion stiffness. It is also noted that the large sweep angle has negative aeroelastic effect on both flutter speed and control effectiveness because of the large negative bending-torsion coupling. Therefore the bending stiffness of the SAW of this particular wing planform also plays a significant role in the control effectiveness and has been taken into consideration in the optimization process.

\section{ACKNOWLEDGEMENT}

The authors acknowledge the financial support from the UK EPSRC, BAE Systems, and MBDA and the technical advices received from the industrial advisors Prof. C. Warsop, Dr A. Hussain, and Dr T. Machell.

(C) Authors 2009

\section{REFERENCES}

1 Campanile, L. F. and Sachau, D. The belt-rib concept: a structronic approach to variable camber. J. Intell. Mater. Syst. Struct., 2000, 11 (3), 215-224.

2 Bae, J.-S., Seigler, T. M., and Inman, D. J. Aerodynamic and static aeroelastic characteristics of a variable-span morphing wing. J. Aircr., 2005, 42(2), 528-534.

3 Yarf-Abbasi, A. and Fielding, J. Design and development of the eclipse and demon demonstrator UAV's. In Proceedings of the 26th Congress of International Council of Aeronautical Sciences (ICAS 2008), Canada, September 2008.

4 Musgrove, R. G. Eccentric actuator. US Patent 4,286,761, 1981.

5 Librescu, L. and Khdeir, A. A. Aeroelastic divergence of swept-forward composite wings including warping restraint effect. AIAA J., 1988, 26, 1373-1377.

6 Librescu, L. and Thangjitham, S. Analytical study on static aeroelastic behaviour of swept-forward composite wing structures. J. Aircr., 1991, 28, 151-157.

7 Weisshaar, T. A. Divergence of swept-forward composite wings. J. Aircr., 1980, 17, 442-448.

8 Hollowell, S. J. and Dugundji, J. Aeroelastic flutter and divergence of stiffness coupled graphite/epoxy cantilevered plates. J. Aircr., 1984, 21, 69-76.
9 Lottati, I. Flutter and divergence aeroelastic characteristics for composite forward swept cantilever wing. J. Aircr., 1985, 22, 1001-1007.

10 Georghiades, G. A., Guo, S., and Banerjee, J. R. Flutter characteristics of laminated wings. J. Aircr., 1996, 33, 1204-1206.

11 Guo, S., Banerjee, J. R., Cheung, C.W., and Butler, R. Gust alleviation and flutter suppression of an optimised composite wing. In Proceedings of the International Forum on Aeroelasticity and Structural Dynamics, Manchester, UK, June 1995.

12 Lillico, M., Butler, R., Banerjee, J. R., and Guo, S. Optimum design of high aspect ratio wings subject to aeroelastic constraints. In Proceedings of the 36th AIAA/SME/ ASEC/AHS/ASC Structures, Structural Dynamics and Materials Conference, April 1995, pp. 558-566.

13 Lillico, M., Butler, R., Guo, S., and Banerjee, J. R. Aeroelastic optimisation of composite wings using the dynamic stiffness method. Aeronaut. J., 1997, 101, 77-86.

14 Guo, S. Aeroelastic optimisation of an aerobatic aircraft wing structure. Aerosp. Sci. Technol., 2007, 11, 396-404.

15 Guo, S., Banerjee, J. R., and Cheung, C. W. The effect of laminate lay-up on the flutter speed of composite wings. Proc. IMechE, Part G: J. Aerospace Engineering, 2003, 217, 115-122. DOI: 10.1243/095441003322297225.

16 Guo, S., Chen, W., and Cui, D. Aeroelastic tailoring of composite wing structures by laminate layup optimisation. AIAA J., 2006, 44, 3146-3149.

17 Guo, S., Chen, W., and Cui, D. Optimisation of composite wing structures for maximum flutter speed. In Proceedings of the First AIAA Multidisciplinary Design Optimisation Specialist Conference, The 46th AIAA/ ASME/ASCE/AHS/ASC Structures, Structural Dynamics, and Materials Conference, Austin, 2005.

18 Kudva, J. N., Martin, C. A., and Scherer, L. B. Overview of the DARPA/AFRL/NASA smart wing program. Proc. Soc. Photo-Opt. Instrum. Engrs, 1999, 3674, 230-236.

19 Armanios, E. A. and Badir, A. M. Free vibration analysis of anisotropic thin walled closed cross-section beams. AIAA J., 1995, 33, 1905-1910.

20 Banerjee, J. R. and Williams, F. W. Coupled bendingtorsional dynamic stiffness matrix for Timoshenko beam elements. Comput. Struct., 1992, 42, 301-310.

21 Banerjee, J. R. and Williams, F. W. Free vibration of composite beams - an exact method using symbolic computation. J. Aircr., 1995, 32, 636-642.

22 Kollar, L. P. and Springer, G. S. Mechanics of composite structures, 2003, ch. 6 (Cambridge University Press, Cambridge, UK).

23 Wittrick, W. H. and Williams, F. W. A general algorithm for computing natural frequencies of elastic structures. Q. J. Mech. Appl. Math., 1971, 24, 263-284.

24 Liani, E. and Guo, S. Potential-flow-based aerodynamic analysis and test of a flapping wing. In Proceedings of the 37th AIAA Fluid Dynamics Conference, Miami, Florida, AIAA-2007-4068, 2007.

25 Theodorsen, T. General theory of aerodynamic instability and the mechanism of flutter. NACA technical report 496, 1949, pp. 413-433.

26 Megson, T. H. G. Aircraft structures for engineering students, 3rd edition, 1999, ch. 13 (Butterworth Heinmann, Oxford, UK). 


\section{APPENDIX}

\section{Notation}

$A_{\mathrm{e}}$

$A_{i j}$

$A(s), B(s), C(s)$

$b$

$C_{i j}$

$C_{\mathrm{L}}$

(D)

$E_{i}$

$E I, G J, C K$

$f_{\mathrm{v}}$

FI

$G_{i j}$

$h$

$I_{\mathrm{P}}$

$\left(\mathbf{K}_{\mathrm{D}}(\omega)\right)$

$L, M_{x}, M_{y}$ cross-sectional area of the

closed-section beam

components of the in-plane

stiffness matrix (A)

reduced axial, coupling, and shear

stiffness of the closed-section

beam

wing semi-chord

stiffness coefficients of the

closed-section beam

wing lift coefficient

generalized damping matrix

of the structure

ply Young's modulus in the $i$

direction

bending, torsion, and

bending-torsion coupling

rigidities

objective function

failure index

ply shear modulus in the $i-j$ plane transverse displacement of the wing box beam

polar mass moment of inertia per

unit length of the wing box beam

frequency dependent generalized

dynamic stiffness matrix

lift force, bending moment, and torque applied to the wing box beam

\section{LE}

$m$

$\{\boldsymbol{q}\}$

$(\mathbf{Q A})_{\mathrm{R}},(\mathbf{Q A})_{\mathrm{I}}$

$S$

SAW

TE

$V_{\mathrm{d}}, V_{\mathrm{f}}, V_{\mathrm{R}}$

$X_{\alpha}$

$X_{\mathrm{t}}, X_{\mathrm{c}}, Y_{\mathrm{t}}, Y_{\mathrm{c}}$

$\alpha$

$\delta_{\mathrm{LE}}, \delta_{\mathrm{TE}}$

$\varepsilon_{x}, \varepsilon_{y}, \gamma_{x y}$

$\theta$

$v_{12}$

$\rho$

$\sigma_{x}, \sigma_{y}, \tau_{x y}$

$\phi$

$\omega$

$\omega_{\mathrm{f}}$ leading edge

mass per unit length of the wing box beam

generalized coordinates of the

structure

real and imaginary parts of the

generalized unsteady

aerodynamic matrix

in-plane shear strength

seamless aeroelastic wing

trailing edge

divergence, flutter, and reversal

speed

distance between the mass and elastic axes of the wing box cross-section

ply tensile and compressive strength in longitudinal and transverse directions

wing angle of attack

leading and trailing edge control surface deflections

direct strain in the $x$ and $y$-axis; shear strain in the $x-y$ plane laminar fibre orientation ply Poisson's ratio in the 1-2 plane density

direct stress in the $x$ and $y$-axis;

shear stress in the $x-y$ plane

twist of the wing box beam

frequency of the wing

flutter frequency 